\title{
Syndecan-1 is the primary heparan sulfate proteoglycan mediating hepatic clearance of triglyceride-rich lipoproteins in mice
}

\author{
Kristin I. Stanford, ${ }^{1,2}$ Joseph R. Bishop, ${ }^{1}$ Erin M. Foley, ${ }^{1,2}$ Jon C. Gonzales, ${ }^{1,2}$ Ingrid R. Niesman, ${ }^{1}$
} Joseph L. Witztum, ${ }^{3}$ and Jeffrey D. Esko',2

1Department of Cellular and Molecular Medicine, ${ }^{2}$ Biomedical Sciences Graduate Program, and ${ }^{3}$ Department of Medicine, University of California, San Diego, La Jolla, California, USA.

\begin{abstract}
Elevated plasma triglyceride levels represent a risk factor for premature atherosclerosis. In mice, accumulation of triglyceride-rich lipoproteins can occur if sulfation of heparan sulfate in hepatocytes is diminished, as this alters hepatic lipoprotein clearance via heparan sulfate proteoglycans (HSPGs). However, the relevant HSPG has not been determined. In this study, we found by RT-PCR analysis that mouse hepatocytes expressed the membrane proteoglycans syndecan-1, -2 , and -4 and glypican-1 and -4. Analysis of available proteoglycandeficient mice showed that only syndecan-1 mutants $\left(S d c 1^{-/-}\right.$mice) accumulated plasma triglycerides. $S d c 1^{-/-}$ mice also exhibited prolonged circulation of injected human VLDL and intestinally derived chylomicrons. We found that mice lacking both syndecan-1 and hepatocyte heparan sulfate did not display accentuated triglyceride accumulation compared with single mutants, suggesting that syndecan-1 is the primary HSPG mediating hepatic triglyceride clearance. Immunoelectron microscopy showed that syndecan-1 was expressed specifically on the microvilli of hepatocyte basal membranes, facing the space of Disse, where lipoprotein uptake occurs. Abundant syndecan-1 on wild-type murine hepatocytes exhibited saturable binding of VLDL and inhibition by heparin and facilitated degradation of VLDL. Furthermore, adenovirus-encoded syndecan-1 restored binding, uptake, and degradation of VLDL in isolated $S d c 1^{-/-}$hepatocytes and the lipoprotein clearance defect in $S d c 1^{-/-}$ mice. These findings provide the first in vivo genetic evidence that syndecan-1 is the primary hepatocyte HSPG receptor mediating the clearance of both hepatic and intestinally derived triglyceride-rich lipoproteins.
\end{abstract}

\section{Introduction}

Because elevated plasma triglycerides constitute an independent risk factor for premature atherosclerosis, much interest exists in determining the factors that affect their synthesis and turnover $(1,2)$. Circulating triglyceride-rich lipoproteins (TRLs) arise from dietary fats in the intestine (chylomicrons) and de novo-synthesized lipids in the liver (VLDL). In the circulation, chylomicron and VLDL triglycerides undergo hydrolysis by lipoprotein lipase (LPL), which is immobilized on receptors on endothelial cells $(3,4)$. The surrounding tissues then take up the liberated free fatty acids for energy generation, membrane lipid synthesis, or storage as lipid droplets. Remnant lipoproteins arising from LPL-mediated lipolysis are cleared in the liver by multiple endocytic receptors, including the LDL receptor (LDLR) and heparan sulfate proteoglycans (HSPGs) (5-8). Recent genetic studies in mice have demonstrated the importance of these 2 classes of receptors in TRL clearance in vivo $(9,10)$.

The identity of the physiologically relevant HSPG in hepatocytes that mediates remnant particle clearance in vivo has not been determined. Animal cells express multiple HSPGs, including 4 transmembrane syndecans, 6 glycosylphosphatidylinositol-anchored glypicans, an alternatively spliced form of CD 44 (v3), TGF- $\beta$ type III receptors (betaglycan), neuropilin-1 (11), and 4 secreted proteoglycans, perlecan, agrin, collagen XVIII, and serglycin (12). Syndecans (13-16) and perlecan $(14,17,18)$ have been shown to mediate the internalization of model remnant lipoproteins or TRL preparations enriched in LPL or apoE. Syndecan-1 can also mediate binding and

Conflict of interest: The authors have declared that no conflict of interest exists. Citation for this article: J. Clin. Invest. 119:3236-3245 (2009). doi:10.1172/JCI38251. uptake of chylomicron remnants by HepG2 liver cells in vitro based on antisense and antibody inhibition experiments (19). In vivo evidence pointing to specific hepatic proteoglycans mediating TRL clearance is more indirect. Yu et al. found that chylomicron remnants labeled with a fluorescent dye co-cluster with syndecan-1 on hepatocytes in the space of Disse (20), consistent with cell culture data indicating that clustering of syndecan may facilitate its internalization by endocytosis $(13,21)$. However, the authors opposed a functional role for syndecan-1 as a remnant receptor, suggesting that syndecan-1 acted merely as a chaperone to other receptors. As an added complication, overexpression of hepatic syndecan-1 in mice by infection with an adenoviral construct actually induced hyperlipidemia (22), but this may have reflected liver damage indicated by marked hepatocyte proliferation, apoptosis, and increased plasma alanine aminotransferase levels.

It is important to determine the relevant HSPG in the liver and its functional role in remnant clearance, because this would set the stage for further mechanistic studies of TRL uptake and processing and provide a candidate gene for allelic analysis in individuals with hypertriglyceridemia. In the current study, we examined available mutants in membrane HSPGs and found that mice deficient in syndecan-1 (Sdc1-/- mice) had elevated plasma triglycerides under fasting conditions and exhibited delayed hepatic clearance of dietary triglycerides and injected VLDL. Reconstitution of syndecan-1 expression in hepatocytes in vivo restored normal triglyceride metabolism. The absence of syndecan- 1 also caused a decrease in the binding, uptake, and degradation of VLDL particles in isolated primary hepatocytes. Our findings show that syndecan- 1 is the hepatic HSPG receptor involved in TRL clearance. 

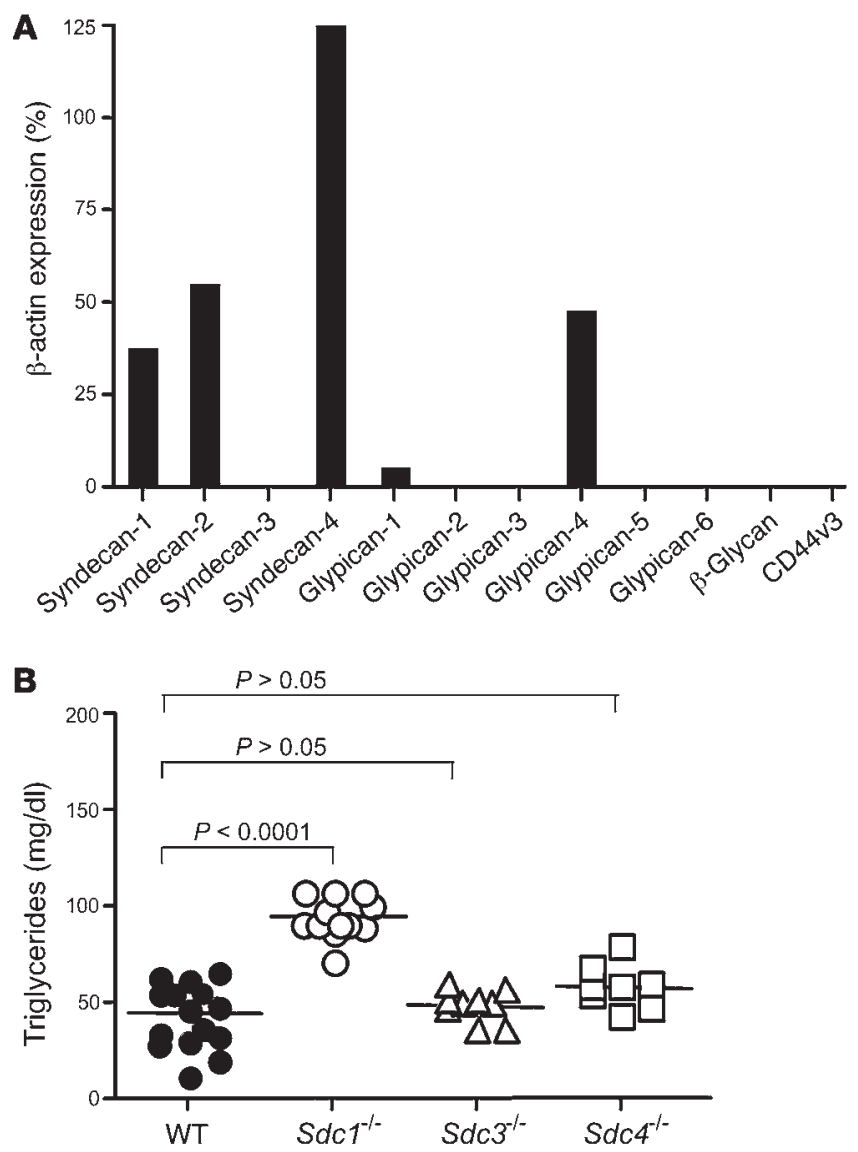

Figure 1

RT-PCR analysis of membrane HSPGs and hypertriglyceridemia in Sdc1 $1^{--}$mice. (A) Transcript levels of the membrane proteoglycan core proteins were measured in isolated hepatocytes. The numbers represent the level of expression compared with the housekeeping gene $\beta$-actin, using $\mathrm{C}_{\mathrm{T}}$ values from triplicate assays according to the Stratagene manual. Error bars are not shown because they are factored into the final calculation. Comparable results were obtained in 2 independent preparations of RNA. (B) Triglycerides were measured in plasma samples from fasted male and female mice of indicated genotypes. Wild-type $(n=14)$, Sdc1 $1^{-/-}(n=13), S_{d c} 3^{-/}(n=10)$, Sdc $4^{--}$ $(n=8)$. Horizontal bars indicate mean values.

\section{Results}

Sdc1-/- mice accumulate plasma triglycerides. To identify the relevant HSPGs in hepatic clearance, we first determined the array of proteoglycan core proteins expressed by murine hepatocytes. Quantitative RT-PCR (qRT-PCR) using intron-spanning primers to all of the known membrane proteoglycans (Supplemental Table 1; supplemental material available online with this article; doi:10.1772/ JCI38251DS1) showed that freshly purified hepatocytes expressed transcripts for syndecan-1, -2 , and -4 and glypican- 1 and $-4(n=3)$ (Figure 1A). Since the probe sets were validated with preparations of RNA from other tissues, the absence of detectable mRNA for other proteoglycans (e.g., syndecan-3, other glypicans, betaglycan, and CD44v3) was judged important. A similar expression pattern for syndecans has been reported in rat hepatocytes (23).

Of the 5 membrane proteoglycan transcripts detected in hepatocytes, murine mutants containing systemic null alleles for syndecan-1 and -4 were available for further study. Analysis of fasted animals showed that only $S d c 1^{-/-}$mice had elevated plasma triglyceride levels, which were approximately 2 -fold higher than those of wild-type mice $\left(95 \pm 11 \mathrm{mg} / \mathrm{dl}\right.$ in $S d c 1^{-/-}$mice $[n=13]$ vs. $44 \pm 19 \mathrm{mg} / \mathrm{dl}$ in wild-type mice $[n=14] ; P<0.0001)$. $S d c 4^{-/-}$(and, as an added control, $S d c 3^{-/}$mice) had normal plasma triglyceride levels $(n=8)$ (Figure 1B). Plasma cholesterol levels were unaffected in $S d c 1^{-/-}$mice $\left(70 \pm 1 \mathrm{mg} / \mathrm{dl}\right.$ in $S d c 1^{-/-}[n=13]$ vs. $74 \pm 5 \mathrm{mg} / \mathrm{dl}$ in wild-type mice $[n=14] ; P=0.3782)$.

Buoyant density ultracentrifugation of fasting plasma lipoproteins from $S \mathrm{dc1}^{-/-}$and wild-type mice showed that triglyceride accumulation occurred in particles of $\delta<1.006 \mathrm{~g} / \mathrm{ml}$ and $\delta=1.006-1.019$ $\mathrm{g} / \mathrm{ml}$, respectively, whereas LDL and HDL triglycerides were unaffected (Figure 2A). Only minor differences in the amounts of cholesterol in the separated lipoprotein classes were noted (Figure 2B). Analysis of lipoproteins of $\delta<1.019 \mathrm{~g} / \mathrm{ml}$ by SDS-PAGE showed that they had apoB-48, apoB-100, apoE, and apoC, characteristic of VLDL particles and chylomicron remnants (Figure 2C). Analysis of the lipoproteins by gel filtration fast-phase liquid chromatography (FPLC) showed that the triglyceride-rich particles eluted like chylomicron remnants and VLDL, with no obvious change in cholesterol content (Figure 2, D and E). A small decrease in cholesterol was noted in small, high-density particles, but we did not further investigate the characteristics of these particles. The lipoprotein phenotype of $S \mathrm{dc}^{-1-}$ mice was virtually identical to that reported previously for $\mathrm{Ndst} 1^{\mathrm{f} / \mathrm{f}} \mathrm{AlbCr} \mathrm{C}^{+}$mice, which produce undersulfated heparan sulfate chains in hepatocyte proteoglycans (9).

Sdc1 $1^{-1-}$ mice exhibit delayed plasma clearance of both VLDL and dietary triglycerides. Prior studies showed that $\mathrm{Ndst} 1^{\mathrm{f} / \mathrm{f}} \mathrm{AlbCre} \mathrm{C}^{+}$mice displayed altered hepatic clearance of triglycerides, which suggested that $S d c 1^{-/-}$mice might exhibit a similar phenotype (9). VLDL clearance was therefore measured by intravenous injection of a bolus of human VLDL and periodic blood sampling to determine human apoB-100 levels by ELISA using mAb MB47. As shown in Figure $3 \mathrm{~A}$, the initial rate of clearance of human VLDL was reduced about 2 -fold in $S d c 1^{-/-}$mice compared with the wild-type $\left(t_{1 / 2}=92 \pm 18\right.$ minutes in $S d c 1^{-/}$mice vs. $46 \pm 7$ minutes in wild-type mice, determined from linear regression of semi-log plots; $P=0.0009, n=6$ ). Although the absolute clearance rates differed from previous data obtained from studies of $\mathrm{N}$-deacetylase/ $\mathrm{N}$-sulfotransferase-1-deficient (Ndst1-deficient) mice, the fold difference between mutant and wild-type mice was comparable (9).

The clearance rate of intestinally derived TRLs was also measured by vitamin A excursion studies. Fasted mice were given a bolus mixture of $\left[{ }^{3} \mathrm{H}\right]$ retinol and corn oil by oral gavage, and blood was sampled at various time points to determine the plasma level of ${ }^{3} \mathrm{H}$ counts. In the intestine, $\left[{ }^{3} \mathrm{H}\right] \mathrm{retinol}$ is converted to fatty acid esters and incorporated into newly made chylomicrons, and its only route of removal is through clearance in the liver (24). As shown in Figure $3 \mathrm{~B}$, the area under the curve for $S d c 1^{-/-}$mice was 2 -fold greater than that for wild-type, indicating that the mutant cleared intestinally derived lipoproteins at a slower rate $(P=0.0034)$. After 12 hours, most of the tracer had been cleared in both mutant and wild-type animals, consistent with previous data showing that LDLRs also can clear plasma TRLs $(9,24,25)$. Clearance of plasma triglycerides was similarly affected (Figure 3B, inset). The data presented in Figure 3 , A and B, indicate that syndecan-1 plays a key role in the clearance of both hepatic (VLDL) and intestinally derived TRLs.

Since $S d c 1^{-/}$mice were created by conventional gene targeting methods (26), syndecan-1 expression was diminished in all tissues. Thus, other processes related to triglyceride synthesis, secre- 


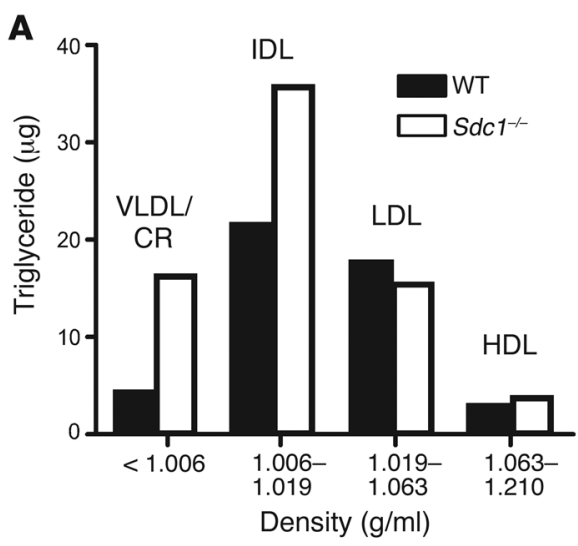

D

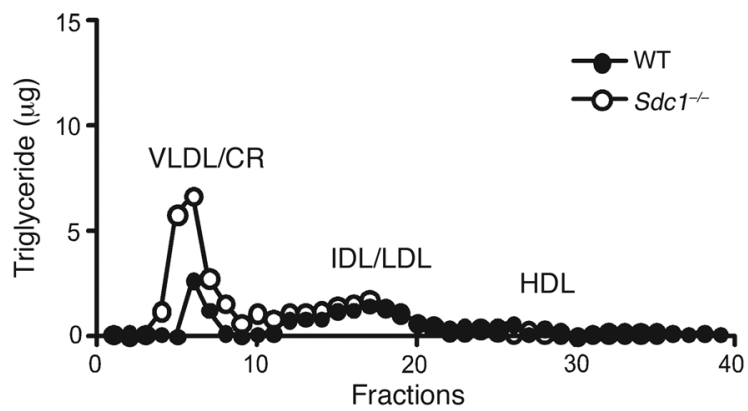

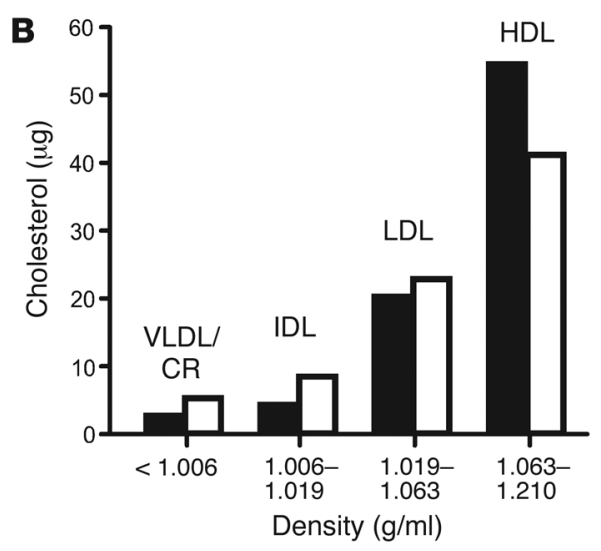

C

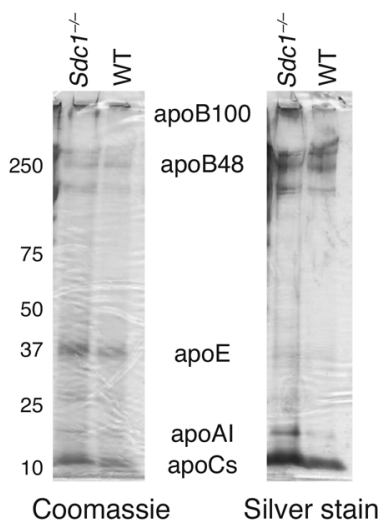

Figure 2

E

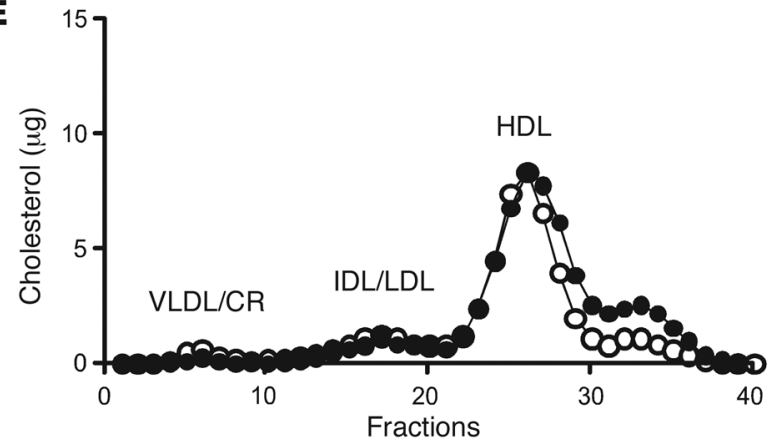

Hypertriglyceridemia in Sdc1-- mice. (A and B) Triglyceride (A) and cholesterol (B) levels were measured in lipoprotein subclasses separated by preparative density ultracentrifugation. Each value is from pooled plasma derived from 10 mice. (C) Samples of purified lipoproteins $(\delta<1.006$ $\mathrm{g} / \mathrm{ml}$ ) were analyzed by gradient SDS-PAGE, and the individual apolipoproteins were visualized by Coomassie blue or silver staining. (D and E) Plasma triglycerides (D) and cholesterol (E) were analyzed by FPLC.

tion, or lipolysis in non-hepatic tissues could be affected in the mutant. To determine how the mutation affected overall synthesis and secretion of triglycerides, we injected the mice with Triton WR-1339, which inhibits lipolysis and lipoprotein clearance (27), and measured plasma triglycerides at various time points (Supplemental Figure 1). Analysis of the data showed that triglyceride secretion rates did not differ significantly between $S d c 1^{-/-}$ and wild-type mice $(0.51 \pm 0.11 \mathrm{mg} / \mathrm{min}$ vs. $0.38 \pm 0.07 \mathrm{mg} / \mathrm{min}$, respectively). To test whether lipolysis might be altered in tissues, we measured lipolytic activity in cell-free gonadal fat pad extracts. No difference in activity in extracts prepared from wild-type and $S d c 1^{-/}$mice was observed (Supplemental Figure 2A). Furthermore, syndecan-1 was not detected among the various HSPGs expressed in this tissue (Supplemental Figure 2B). We recently showed that altering sulfation of HSPGs in endothelial cells does not alter plasma triglyceride metabolism as well (28). Thus, these findings suggest that the hyperlipidemia associated with syndecan-1 deficiency was more likely due to defects in hepatic clearance than to non-hepatic processing of triglycerides.

Additional evidence was obtained by intravenously injecting $S d c 1^{-/-}$mice with adenovirus containing either $S d c 1$ or GFP cDNAs. Under these conditions, more than $95 \%$ of the adenovirus is cleared by the liver (29), leading to hepatic-specific expression of syndecan-1. Three weeks after infection, a bolus of $\left[{ }^{3} \mathrm{H}\right]$ retinol and corn oil was administered by gavage and the rate of clearance was measured. Infection with adenovirus containing syndecan-1 cDNA (AdSdc1) partially restored expression of syndecan-1 (Sup- plemental Figure 3A), but nevertheless normalized clearance compared with $S d c 1^{-/-}$mice infected with $\operatorname{AdGFP}(P=0.0037)$, and the excursion curve was similar to that of wild-type mice (Figure 3C). These findings show that hepatic syndecan- 1 is both necessary and sufficient to clear plasma triglycerides. They contrast the results of a previous study, which showed that syndecan-1 overexpression leads to hypertriglyceridemia, which may reflect differences in viral load, timing of the lipid analyses relative to viral infection, or acute liver injury in the earlier study (22).

Syndecan-1 is the primary HSPG mediating hepatic clearance. The data presented thus far show that the hyperlipidemia in $\mathrm{Sdc1} 1^{-/}$ mice resembles the phenotype of $N d s t 1 / f / f A l b C r e^{+}$mice, which produce undersulfated heparan sulfate chains in hepatocytes due to a deficiency of a specific sulfotransferase, Ndst1. To test whether other hepatocyte HSPGs can affect plasma triglyceride levels, $S d c 1^{-/-}$mice were interbred with $N d s t 1 f / f A l b C r e^{+}$mice, which resulted in undersulfation of heparan sulfate chains on syndecan as well as other hepatocyte-derived proteoglycans. Analysis of fasting plasma triglycerides showed that compounding the mutations did not result in accumulation of triglycerides to a greater extent than in either single mutant (Figure 4A; $P=0.1373$ ). The double mutant also displayed delayed $\left[{ }^{3} \mathrm{H}\right]$ retinol clearance to the same extent as $S d c 1^{-/-}$and $N d s t 1 A l b C r e^{+}$mutants (Figure 4B). The slightly diminished effect in the double mutant was not significant $(P=0.6670)$. These data indicate that the heparan sulfate chains on syndecan-1 are responsible for plasma triglyceride clearance mediated by hepatic proteoglycans. 


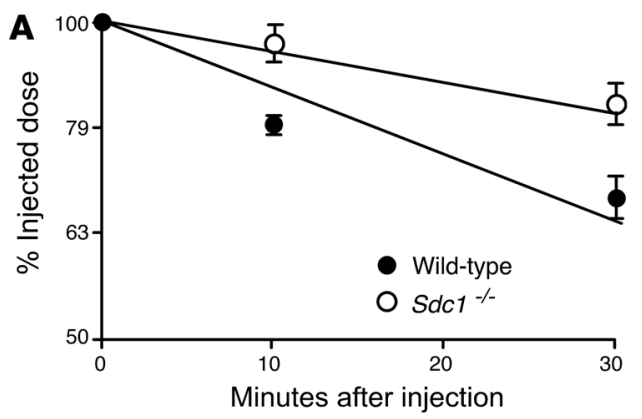

B
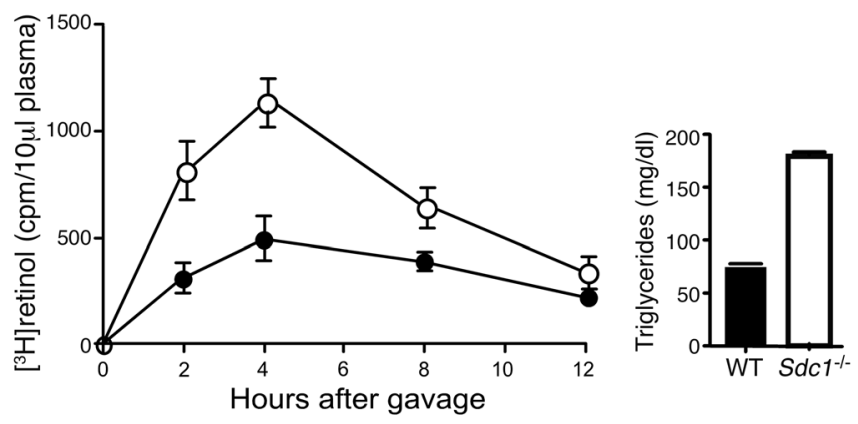

C

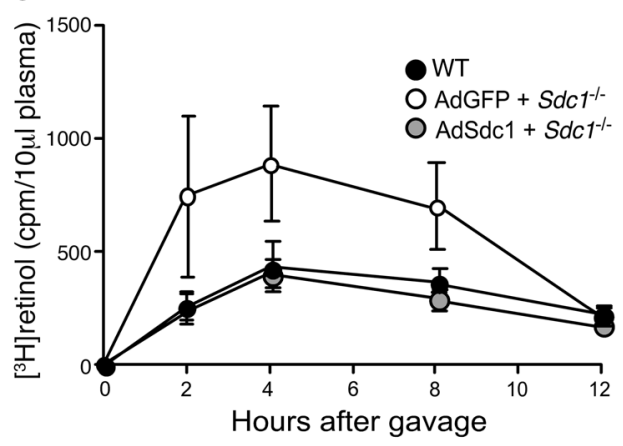

Syndecan-1 is localized on microvilli of hepatocytes in the space of Disse. Prior studies have shown that syndecan-1 is located on basal membrane of the hepatocytes facing the space of Disse $(30,31)$. To confirm these findings, we examined immunofluorescence micrographs of cryosections prepared from wild-type, $S d c 1^{-/-}$, and

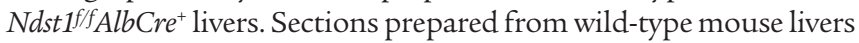
showed syndecan-1 localization around the sinusoids (Supplemental Figure 4A), whereas livers from $S d c 1^{-/}$mice did not stain, confirming the specificity of the antibody (Supplemental Figure 4B).

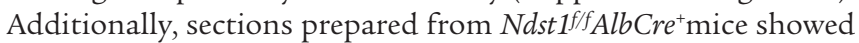
that syndecan-1 was localized around the sinusoids as in wild-type liver sections, indicating that altering the sulfation of the heparan sulfate chains had no effect on the distribution of syndecan-1 (Supplemental Figure 4C). In contrast to these findings, syndecan-2 was present mainly on sinusoidal endothelial cells, whereas syndecan-4 was ubiquitously expressed over the entire hepatocyte surface (data not shown). Electron microscopy of immunogoldlabeled sections showed enrichment of syndecan- 1 on the microvilli extending from the basal surface of the hepatocytes (Supplemental Figure 4D). Thus, syndecan-1 is positioned appropriately to encounter remnant TRLs entering the space of Disse.

Syndecan-1 can mediate binding, uptake, and degradation of VLDL. To determine whether syndecan-1 could directly mediate the binding

\section{Figure 3}

Sdc1-1- mice exhibit delayed plasma clearance of triglycerides and postprandial lipoproteins. (A) Clearance of human VLDL apoB-100 was measured by ELISA using human apoB-100-specific mAb MB47. Representative data from 3 different experiments is shown and plotted on a semi-log scale. Wild-type mice, $t_{1 / 2}=46 \pm 7$ minutes ( $n=6$ mice); $S d c 1^{-1-}$ mice, $t_{1 / 2}=92 \pm 18 \mathrm{~min}(n=6$ mice $)$. The difference in $t_{1 / 2}$ between the genotypes was significant $(P=0.0009)$. (B) Retinol ester clearance was measured in wild-type (filled circles, $n=3$ ), and $S d c 1^{-/-}$ (open circles, $n=3$ ) mice. Animals were fasted for 4 hours and given $200 \mu$ l of corn oil containing $\left[{ }^{3} \mathrm{H}\right]$ retinol by gavage. Blood samples were taken and radioactivity remaining in $10 \mu \mathrm{l}$ of serum was determined by scintillation counting. The values are expressed as mean \pm SD. The areas under the curve were 4,100 $\pm 1,200$ for the wild-type and $8,400 \pm 30$ for $S d c 1^{-1-}$ mice. Clearance was significantly delayed in Sdc $1^{-1-}$ mice compared with wild-type $(P=0.0034)$. Right: Triglyceride values were measured 4 hours after injection. (C) $S d c 1^{-/-}$mice were injected with AdSdc1 ( $n=6$ mice) or AdGFP ( $n=6$ mice). Plasma retinol ester levels were measured as described above and compared with wild-type mice (filled circles). The areas under the curve were $3,700 \pm 1,100$ for wild-type, $7,400 \pm 2,600$ for AdGFP Sdc1-1-, and $3,200 \pm 900$ for AdSdc1 Sdc1-1- Animals treated with AdSdc1 demonstrated clearance similar to that wild-type animals (gray circles, $P=0.1272)$ and significantly faster clearance than $S d c 1^{-1-}$ mice treated with AdGFP $(P=0.0037)$.

of physiologically plausible concentrations of unmodified VLDL by primary hepatocytes, cells were isolated from wild-type mice and incubated with labeled and unlabeled native VLDL at $4{ }^{\circ} \mathrm{C}$. Normal primary hepatocytes bound ${ }^{125} \mathrm{I}-\mathrm{VLDL}$ in a saturable manner, and the signal was reduced by the addition of heparin (Figure 5A). Specific binding was then determined by subtracting the counts obtained in the presence of heparin from the counts obtained in its absence (Figure 5A). Fitting the data to a conventional single-site binding equation yielded a $B_{\max }$ value of $8.2 \pm 1.1 \mu \mathrm{g}$ VLDL protein/ $\mathrm{mg}$ cell protein and $K_{\mathrm{D}}$ of $43 \pm 10 \mu \mathrm{g} / \mathrm{ml}(\sim 2.2 \mathrm{nM})\left(R^{2}=0.9760\right)$. From the $B_{\max }$ value, we calculated that hepatocytes expressed approximately $1.4 \times 10^{6}$ binding sites/cell, assuming that the average size particle had a diameter of $40 \mathrm{~nm}$ and a mass of $2 \times 10^{7} \mathrm{kDa}$, and that protein represented $1.8 \%$ of the mass. Binding was also sensitive to dilution with nonradioactive VLDL, yielding specific binding data comparable to that obtained by heparin inhibition (Figure $5 \mathrm{~B}$ ) ( $B_{\max }$ value of $9.1 \pm 1 \mu \mathrm{g}$ VLDL protein/mg cell protein and a $K_{\mathrm{D}}$ of $\left.51 \pm 9 \mu \mathrm{g} / \mathrm{ml} ; R^{2}=0.9871\right)$. Much of the binding depended on syndecan-1, since specific binding was reduced on average by 6 -fold \pm 1 -fold in primary hepatocytes derived from $S d c 1^{-/-}$mice compared with wild-type mice (Figure 5C). These findings are consistent with previous studies of other cell types and modified lipoproteins (13, $15,19,32,33)$. Since the normal fasting plasma levels of VLDL in wild-type animals are lower than the calculated $K_{\mathrm{D}}$ values $(8 \pm 3$ $\mu \mathrm{g} / \mathrm{ml}$ plasma VLDL protein vs. $43-51 \mu \mathrm{g} / \mathrm{ml} K_{\mathrm{D}}$ ), we determined that only a portion of syndecan- 1 is normally occupied under these conditions and the system is well poised to accommodate increased levels of remnants in the postprandial state.

Prior studies also have shown that syndecan-1 can mediate lipoprotein uptake and degradation $(13,21)$. Therefore, we examined uptake and degradation of VLDL by incubating wild-type and mutant hepatocytes with $20 \mu \mathrm{g} / \mathrm{ml}$ of ${ }^{125} \mathrm{I}-\mathrm{VLDL}$ at $37^{\circ} \mathrm{C}$. After 1 hour, wild-type cells bound and internalized $4.1 \pm 0.4 \mu \mathrm{g}$ VLDL/ mg cell protein (Figure $6 \mathrm{~A}$ ), which was about $30 \%$ higher than the amount bound at $4^{\circ} \mathrm{C}(3.2 \mu \mathrm{g} / \mathrm{mg}$ cell protein at $20 \mu \mathrm{g} / \mathrm{ml} \mathrm{VLDL}$; Figure 5B). Uptake via syndecan-1 led to degradation of $2.4 \mu \mathrm{g} / \mathrm{mg}$ 

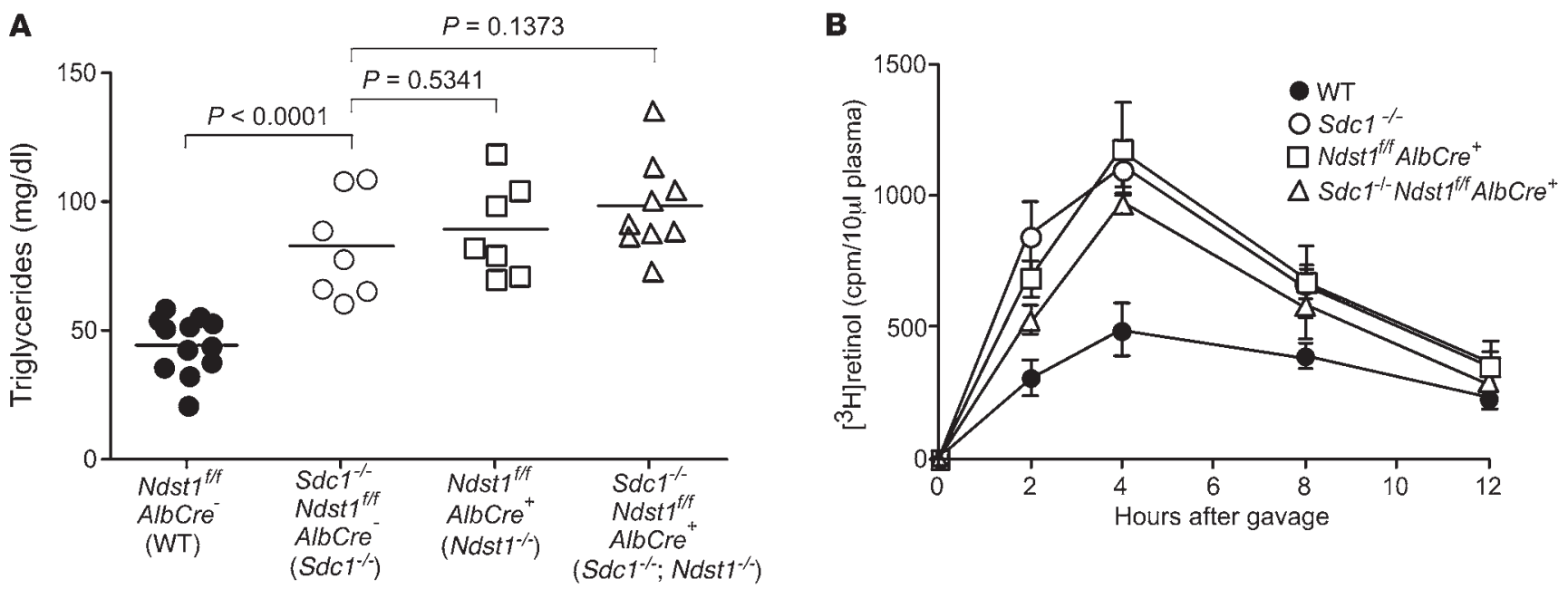

Figure 4

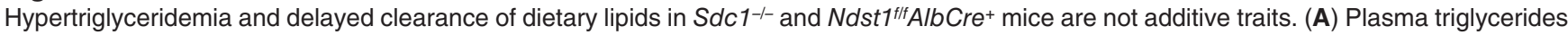
were measured in plasma samples from fasted mice. There was no difference in plasma triglycerides in Sdc $1^{-l-N d s t 1^{f / f}} \mathrm{AlbCre}{ }^{+}($triangles, $n=9$ ), $S d c 1^{-l-N d s t 1^{f / f}} \mathrm{AlbCre}{ }^{-}$(open circles, $n=7$ ), and $\mathrm{Ndst}^{f / f} \mathrm{AlbCre}{ }^{+}$(squares, $n=7$ ) mice, although all 3 genotypes were significantly elevated

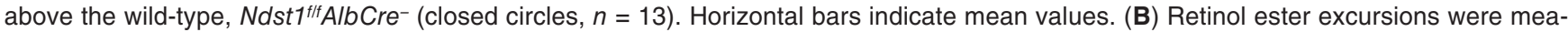

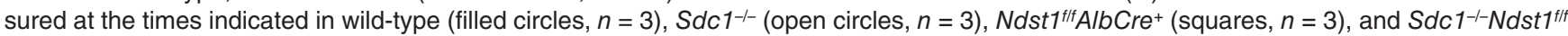
AlbCre+(triangles, $n=3$ ) mice. Animals were fasted for 4 hours in the morning and given $200 \mu$ of corn oil containing $\left[{ }^{3} \mathrm{H}\right] \mathrm{retinol}$ by gavage. Blood samples were taken at the indicated times, and radioactivity remaining in $10 \mu \mathrm{l}$ of serum was determined by scintillation counting. The values are expressed as mean \pm SD. The areas under the curves were 4,100 $\pm 1,200$ for wild-type, 8,400 \pm 300 for Sdc $1^{-l-}, 8,300 \pm 400$ for $\mathrm{Ndst} 1^{t / f} \mathrm{AlbCre} \mathrm{C}^{+}$, and 6,900 $\pm 1,000$ for $S d c 1^{-l-N d s t 1^{f l f}} \mathrm{AlbCre}+$ mice. Clearance was significantly delayed in the Sdc1-l- mice compared with wild-type $(P=0.0034)$, whereas the difference observed between $S d c 1^{-/-}$and $S d c 1^{-/-} \mathrm{Ndst1^{f/f }} A / b C r \mathrm{C}^{+}$animals was not significant $(P=0.1373)$.

of cell protein in 1 hour, as measured by the appearance of acid-soluble, non-chloroform extractable ${ }^{125}$ I counts in the growth medium. $S d c 1^{-/-}$hepatocytes showed a dramatic decrease in both uptake $(1.5 \pm 0.4 \mu \mathrm{g}$ VLDL/mg cell protein; $P<0.005)$ and degradation $(0.4 \pm 0.1 \mu \mathrm{g}$ VLDL/mg cell protein; $P<0.02)$ under these conditions.

To confirm that altered uptake and degradation in $S d c 1^{-1}$ hepatocytes resulted from loss of syndecan-1, we analyzed primary hepatocytes isolated from $S d c 1^{-/-}$mice infected with AdSdc1 or AdGFP. AdSdc1-treated hepatocytes showed increased binding, uptake, and degradation of ${ }^{125}$ I-VLDL compared with hepatocytes derived from mice treated with AdGFP (Figure 6B). Finally, we examined uptake and degradation in hepatocytes derived from mice deficient in LDLRs and in combination with a deficiency of Ndst1. As shown in Figure 6C, the LDLR contributes to binding and uptake, but to a lesser extent than syndecan-1. LDLR expres-

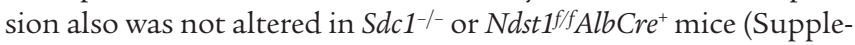
mental Figure 3B). Together, these data indicate that syndecan-1 accounts for the majority of ${ }^{125}$ I-VLDL bound, taken up, and degraded by wild-type primary hepatic parenchymal cells.

\section{Discussion}

The major finding presented in this report is that syndecan- 1 mediates hepatic clearance of TRLs in vivo. This conclusion is based on the observation that TRLs resembling VLDL and VLDL remnants accumulate in fasted $S d c 1^{-/}$mice (Figures 1 and 2) and that the mutant exhibits delayed clearance of TRLs derived from dietary fat (Figure 3). Importantly, syndecan-1 appears to be the principal hepatic HSPG involved in TRL clearance, since compounding the syndecan-1 deficiency with a mutation that affects sulfation of all heparan sulfate chains on hepatocyte HSPGs did not increase the extent of triglyceride accumulation (Figure 4). Syndecan-1, poised on the microvilli of hepatocytes (Supplemental Figure 4), can encounter circulating TRLs that enter the space of Disse. Binding to syndecan-1 showed saturability and inhibition by heparin (Figure 5), and increased expression of syndecan-1 by viral transduction corrected the deficiency in postprandial clearance in the mutant (Figure 3C) and enhanced the uptake and degradation of VLDL in isolated hepatocytes (Figure 6). Taken together, these data provide direct genetic evidence that syndecan- 1 is the primary hepatic proteoglycan receptor mediating TRL clearance.

Our genetic studies of hepatic HSPGs extend previous observations showing that syndecans can mediate lipoprotein uptake in cultured cells. Fuki et al. introduced several syndecan core proteins into Chinese hamster ovary cells, which increased cell association and degradation of lipoproteins enriched in LPL, a protein that may mediate binding to the heparan sulfate chains on syndecan-1 (13). Subsequently, Zeng et al. showed by antisense and antibody inhibition that the uptake of chylomicron remnants by HepG2 liver cells was mediated in part by syndecan-1 (19). Uptake by cultured cells depends on the heparan sulfate chains, based on analysis of mutants altered in heparan sulfate biosynthesis, treatment of cells with heparinases that degrade the heparan sulfate chains, or pharmacological manipulation of glycosaminoglycan biosynthesis (34-42). Conversely, overexpression of human syndecan-1 increased binding and uptake of VLDL by human fibroblasts (15). The data presented here demonstrate that TRL binding and uptake in the liver occur by way of syndecan- 1 and establish the physiologic relevance of those earlier findings.

Syndecan-1, first described by Bernfield and colleagues on mammary epithelial cells (43), is a transmembrane proteoglycan of 

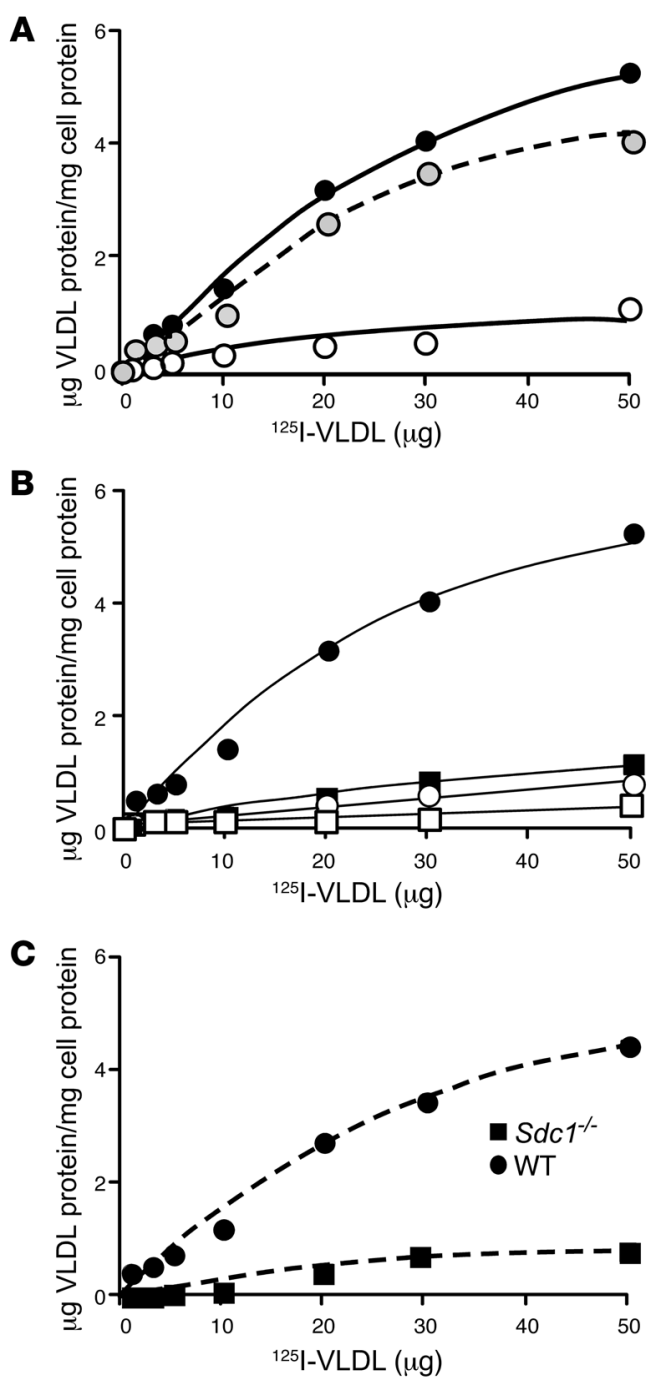

diverse function that modulates cell adhesion and motility, growth factor activation, tumor growth, and microbial infection (43-49). Like other proteoglycans, syndecan undergoes endocytosis and degradation in lysosomes (50). Thus, ligands bound to the heparan sulfate chains can "piggy-back" into the cell (5), which operationally defines syndecan-1 as an endocytic receptor of broad specificity. Syndecan-1 also undergoes proteolytic processing, which results in shedding of ectodomains containing the attached glycosaminoglycan chains (51). Although, to our knowledge, the shedding process has not been studied in liver, cultured hepatocytes accumulate ectodomains in the conditioned medium (our unpublished observations). This finding raises the possibility that shed syndecan-1 ectodomains might bind plasma lipoproteins in the space of Disse and either prevent their escape back into the plasma or facilitate their further processing prior to uptake. The fact that compounding syndecan-1 deficiency with a mutation that affects all heparan sulfate chains produced by hepatocytes has no greater effect on lipoprotein clearance than either mutation alone (Figure 4) suggests that syndecan- 1 might also be responsible for sequestration of lipoproteins in the space of Disse, as suggested previously $(13,19)$.

Syndecan- 1 has 3 attachment sites for heparan sulfate clustered near its $\mathrm{N}$ terminus and up to 2 chondroitin sulfate chains located

\section{Figure 5}

Syndecan-1 mediates binding of VLDL. (A) Wild-type cells were incubated with the indicated concentrations of $125 \mathrm{I}-\mathrm{VLDL}$ in the absence (filled circles) or presence (open circles) of $10 \mathrm{U}$ heparin for 1 hour at $4^{\circ} \mathrm{C}$. The amount of binding observed in the presence of heparin was subtracted from the total to obtain specific binding (dashed line, gray circles). (B) Wild-type (filled circles) and Sdc1-l- (filled squares) hepatocytes were incubated with the indicated concentrations of 125 I-VLDL for 1 hour at $4^{\circ} \mathrm{C}$. A parallel set of cells was incubated under identical conditions with $250 \mu \mathrm{g} / \mathrm{ml}$ of non-radioactive VLDL. Addition of non-radioactive VLDL decreased binding in wild-type hepatocytes (open circles) to nearly the level measured in Sdc1-1- cells (open squares). (C) Deletion of syndecan-1 reduced maximal binding. The counts bound in the presence of excess non-radioactive VLDL in $\mathbf{B}$ were subtracted from the raw data, and the net counts were converted to $\mu \mathrm{g}$ VLDL protein bound $/ \mathrm{mg}$ of cell protein, based on radiospecific activity of the particles $(140 \mathrm{cpm} / \mathrm{ng})$. Each data point represents the average of triplicate analyses, which varied by less than the height of the symbol.

in the membrane proximal region, although the glycosaminoglycan content of liver syndecan-1 has not been determined. The binding of TRLs to the heparan sulfate chains presumably occurs through electrostatic interactions between negatively charged sulfate and carboxyl groups with complementary positively charged domains in the apolipoproteins (apoB and apoE) or lipases (LPL or hepatic lipase) associated with the particles. In general, only 8-12 monosaccharide residues are needed to bind to many proteins, including LPL and apoE (52-55), but the pattern of sulfate groups and uronic acids that mediate TRL binding is unknown. Liver heparan sulfate is unusual in that it is more highly sulfated than heparan sulfate in other tissues $(54,56,57)$. Thus, the high degree of sulfation of the heparan sulfate chains in hepatocyte syndecan-1, compared with that of syndecan- 1 in other tissues, might ensure selective binding of remnant lipoprotein particles to liver syndecan-1. Binding and/or internalization might depend on the multiple interactions between one or more chains on syndecan-1 or syndecan multimers with multiple protein ligands associated with the particles. Clustering of syndecan may in fact trigger internalization by endocytosis $(13,21)$.

The abundance of VLDL binding sites on isolated hepatocytes is also interesting. We estimate from saturation binding curves that wild-type cells express over $10^{6}$ VLDL binding sites, and that syndecan-1 apparently accounts for the majority of them (Figure 5). At first glance, this finding would suggest that syndecan-1 should account for the majority of uptake and degradation of VLDL by hepatocytes. However, the rates of internalization of proteoglycans and other more classical receptors, such as LDLR, vary substantially. In cells that have been studied, endocytosis of syndecans occurs in a clathrin-independent manner with relatively slow kinetics $\left(t_{1 / 2}=20-60\right.$ minutes $)(15,21,58,59)$ compared with clathrinmediated uptake of ligands, e.g., uptake of lipoproteins by LDLRs $\left(t_{1 / 2}=5-10\right.$ minutes $)(60)$. LDLRs are much less abundant $\left(\sim 10^{4}\right.$ to $5 \times 10^{4}$ receptors/cell) than syndecan- 1 receptors $\left(\sim 10^{6}\right.$ receptors/ cell), but their faster rate of internalization might partially offset the higher level of expression of syndecan-1, resulting in perhaps comparable contribution to uptake and clearance. The fact that

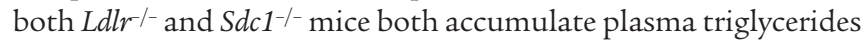
suggests that neither receptor can fully compensate for each other (9), but the composition of the particles that accumulate in these mutants might differ. The quantitative contributions of these 2 receptors to clearance undoubtedly depends on the ligand (chylo- 
A

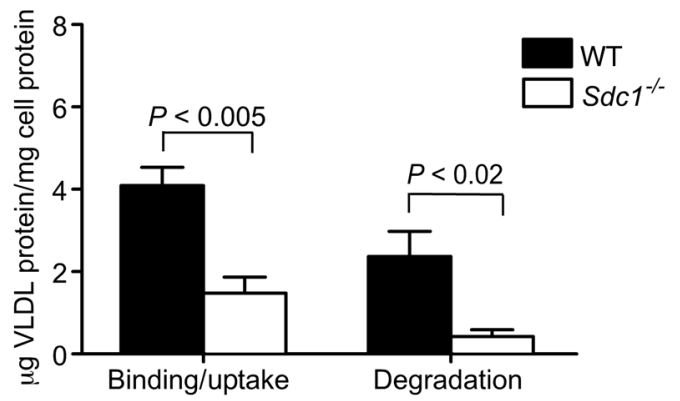

B

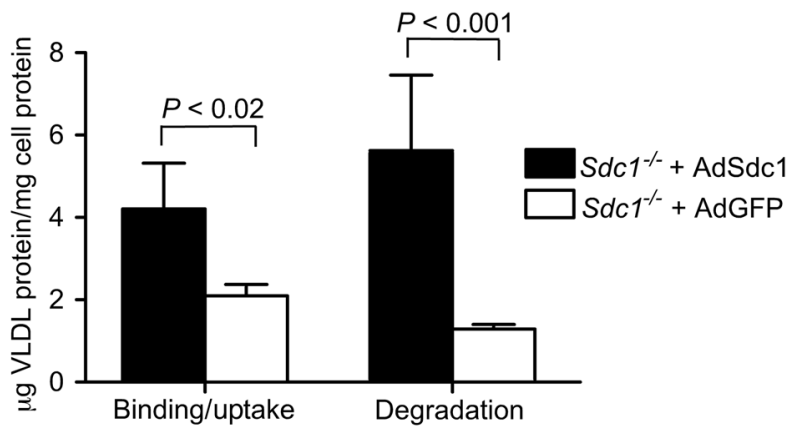

C

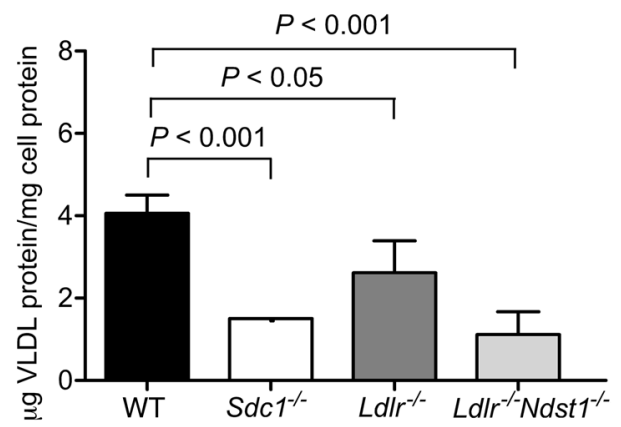

micron remnants, VLDL, and LDL), their apolipoprotein compositions, their concentrations, and other factors. Additional studies of binding, uptake, and degradation in primary hepatocytes are underway to obtain more insight into this problem.

A third class of receptors, LDLR-related proteins (LRPs), have also been implicated in TRL clearance (61). LRP apparently can form a complex with HSPGs (62) and modulate their capacity to bind VLDL. However, inactivation of LRP1 or LRP5 in hepatocytes has no effect on fasting plasma triglyceride levels $(61,63)$, whereas inactivation of syndecan-1 increases plasma triglycerides, suggesting that syndecan- 1 most likely acts independently of LRP receptors under these conditions. LRPs may aid in the metabolism of lipoproteins after dietary challenge or under conditions in which other receptors are occupied or rendered inoperative $(61,63)$. Sorting out the relative contribution of these receptors will require studies of various double mutants lacking syndecan-1, LDLR, and LRPs. It is also unknown whether these 3 receptors undergo coordinate regulation dependent on plasma triglyceride levels. Preliminary experiments show that the relative expression of $\mathrm{mRNAs}$ for LDLR and LRP1 in hepatocytes of $S d c 1^{-/-}$mice is not elevated compared with transcripts in wildtype hepatocytes, and LDLR protein expression does not differ in wild-type, $S d c 1^{-/-}$, or $N d s t 1 f / f A l b C r e^{+}$hepatocytes (Supplemental

\section{Figure 6}

Binding, uptake, and degradation of VLDL at $37^{\circ} \mathrm{C}$. (A) Uptake and degradation of VLDL was measured in wild-type and mutant hepatocytes after 1 hour of incubation with $20 \mu \mathrm{g} / \mathrm{ml}$ of $125 /$-VLDL. The bars represent the sum of binding and internalization under these conditions, or the amount of degradation as determined by acid-soluble, non-chloroform-extractable counts in the medium. Binding plus uptake was reduced 2.7-fold in Sdc1-/ cells. Degradation was reduced by nearly 6-fold. (B) Hepatocytes isolated from Sdc1-/- mice treated with AdSdc1 showed enhanced binding and uptake and increased degradation of ${ }^{125}$ I-VLDL compared with hepatocytes isolated from Sdc1-/mice treated with AdGFP $(P<0.02)$. (C) Binding and uptake were also measured in hepatocytes isolated from wild-type, Sdc1-1-, $\mathrm{Ldlr}^{-1}$, and Ldlr ${ }^{-1-N d s t 1^{1 / f}} \mathrm{AlbCre}{ }^{+}$mice. Uptake and binding were reduced 2 -fold in the Sdc1-1- and $\mathrm{Ldll} \mathrm{r}^{--} \mathrm{Ndst1^{f/f }} \mathrm{AlbCre}{ }^{+}$hepatocytes compared with wildtype $(P<0.001)$, while a slight change was observed in $\mathrm{Ldll}^{--} \mathrm{com}-$ pared with wild-type $(P<0.05)$.

Figure 3B). However, this needs to be examined further in various paired mutants fed normal and high-fat diets.

A step-wise mechanism of binding remnants by syndecan- 1 and hand-off to LDLR or LRP receptors has been proposed $(6,62)$. However, we showed previously that compounding $L d l r^{-/}$with $N d s t 1^{f / f} \mathrm{AlbCr} e^{+}$mice causes an additive accumulation of plasma triglycerides and prolonged the delay in postprandial clearance manifested by each individual mutant (9). Compounding Ndst1 deficiency with $S d c 1^{-/}$does not result in additivity (Figure 4), which implies that the heparan sulfate chains on syndecan-1 are causally tied to the hyperlipidemia in $S d c 1^{-/-}$mutants. By inference then, the heparan sulfate chains on syndecan-1 work independently of LDLR. Additional breeding experiments are underway to make $\mathrm{Ldlr} \mathrm{r}^{--} \mathrm{Sdc1^{-/ }}$ mice, to validate this interpretation of the data. At this time we cannot formally exclude a hand-off mechanism to LRPs, but inactivation of hepatic LRP1 in vivo does not result in reduced clearance of remnant lipoproteins (61), and preliminary data suggest that compounding mutations in Ndst1 and LRP1 does not cause higher plasma lipids than altering $\mathrm{Ndst} 1$ alone (our unpublished observations). Finally, a large body data indicates that proteoglycans can act as independent endocytic receptors for a variety of ligands, both natural and synthetic $(5,64,65)$. Thus, we believe that the genetic data presented here and previously (9), coupled with numerous cell culture studies by other groups over the years $(13-19,21)$, argue for independent action of proteoglycans in the hepatic clearance of triglyceride-rich remnants.

In conclusion, we have determined that syndecan- 1 acts as a primary receptor for remnant TRL clearance in the liver. While further work needs to be done to determine the relative contribution of syndecan- 1 and other receptors to TRL clearance under different dietary conditions, the data presented here suggest that mutations affecting the expression of syndecan-1 or the assembly of the heparan sulfate chains might explain some forms of human dyslipidemias. Studies of patients with unexplained hypertriglyceridemia are underway to explore this possibility.

\section{Methods}

Mice and animal husbandry. Mice deficient in syndecan-1 ( $S d c 1^{-/-}$, provided by P. Park, Harvard University, Cambridge, Massachusetts, USA), syndecan-3 $\left(S d c 3^{-/}\right.$, provided by P. Sanna, The Scripps Research Institute, La Jolla, California, USA), and syndecan-4 (Sdc4 $4^{-/}$, provided by P. Goetinck, Harvard University, Cambridge, Massachusetts, USA) were described previously (26, 66-68). Ndst1fff AlbCre+ mice were described by MacArthur et al. (9). 
All mice were backcrossed more than 10 generations on a C57BL/ 6 background. All animals were housed and bred in vivaria approved by the Association for Assessment and Accreditation of Laboratory Animal Care located in the School of Medicine, UCSD, following standards and procedures approved by the UCSD IACUC. Mice were weaned at 3 weeks, maintained on a 12-hour-light/12-hour-dark cycle, and fed ad libitum with water and standard rodent chow (Harlan Teklad). Genotyping was performed as previously described (9, 66-68).

Hepatocyte isolation. Mouse hepatocytes were isolated essentially as previously described (69). Briefly, mice were anesthetized with isoflurane and perfused via cardiac puncture with $30 \mathrm{ml}$ Krebs-Ringer solution containing $1 \mathrm{mM}$ EDTA $\left(37^{\circ} \mathrm{C}, 7.5 \mathrm{ml} / \mathrm{min}\right)$, followed by perfusion of $30 \mathrm{ml}$ Krebs-Ringer containing $0.15 \mathrm{mM} \mathrm{CaCl}_{2}$ and $0.5 \mathrm{mg} / \mathrm{ml}$ type I collagenase (Sigma-Aldrich). The liver was removed, cut into pieces, and chilled to $4{ }^{\circ} \mathrm{C}$ in $40 \mathrm{ml}$ of Krebs-Ringer solution. The tissue was dispersed by pipetting and filtered through a $70-\mu \mathrm{m}$ nylon cell strainer (BD Falcon). The filtrate was centrifuged for 3 minutes at $50 \mathrm{~g}$ at $4^{\circ} \mathrm{C}$, and the cell pellet was gently resuspended in fresh solution and centrifuged 2 more times. Cells were then resuspended in Williams media supplemented with 10\% FBS and divided equally across the wells of a 6 -well plate precoated with rat tail type I collagen (Sigma-Aldrich). After 3 hours, the medium was replaced with Williams medium supplemented with $10 \%$ FBS, $1 \%$ Insulin-Transferrin-Selenium (Gibco, Invitrogen), $10 \mu \mathrm{g} / \mathrm{ml}$ epidermal growth factor (Invitrogen), $0.1 \mu \mathrm{M}$ dexamethazone, $4.4 \mu \mathrm{M}$ nicotinamide, and $100 \mathrm{U} / \mathrm{ml}$ penicillin and $100 \mu \mathrm{g} / \mathrm{ml}$ streptomycin. All experiments with primary hepatocytes were completed within 48 hours of isolation.

Adenoviruses. AdSdc1 was a gift from Pyong Woo Park (Harvard Medical School, Cambridge, Massachusetts, USA) (70). AdSdc1 and AdGFP were amplified by the UCSD Vector Development Core Facility. Approximately $4 \times 10^{11}$ particles in PBS (71) were injected via the tail vein (72). Mice were used after 3 weeks for the experimental procedures indicated in the text.

qRT-PCR of membrane HSPGs. Total RNAs from mouse, liver, heart, and brain were purchased from Ambion. RNA was isolated from purified hepatocytes from C57BL/6 mice as described previously (73). Samples were reverse transcribed (Superscript III; Invitrogen) and amplified using intron spanning primers (Supplemental Table 1). Quantitation was done by the $2^{-\Delta \Delta \mathrm{Ct}}$ method using $\beta$-actin as control RNAs (74). $\mathrm{C}_{\mathrm{T}}$ values from triplicate assays were used to calculate fold expression as compared with $\beta$-actin, according to the Stratagene manual. Results were verified in 3 independent assays.

Lipoprotein analysis. Plasma samples were prepared from blood drawn via retroorbital bleeding from mice fasted for 4-6 hours in the morning. Total cholesterol and triglyceride levels were determined enzymatically using an automated reader (Cobas Mira; Roche Diagnostics) and kits (Cholesterol High-Performance Reagent from Roche Diagnostics and Triglyceride-SL from Diagnostic Chemicals Ltd).

Lipoproteins were prepared from blood drawn by cardiac puncture using sequential preparative ultracentrifugation. TRLs $(\delta=1.006 \mathrm{~g} / \mathrm{ml})$ were prepared from pooled plasma samples $(n=10$ mice; volume, $5 \mathrm{ml})$ by centrifugation for 12 hours at $135,000 \mathrm{~g}$ in a Beckman 50.3Ti rotor. VLDL remnants and IDL were then collected as the $\delta=1.006-1.019 \mathrm{~g} / \mathrm{ml}$ fraction. LDL and HDL were subsequently collected as the $\delta=1.019-1.063$ and $\delta=1.063-1.21 \mathrm{~g} / \mathrm{ml}$ fractions, respectively. The isolated lipoproteins were dialyzed against PBS and analyzed for lipid content using kits. Plasma lipoproteins were also separated by gel filtration FPLC. Pooled plasma samples were loaded on a Superose 12 FPLC column (Amersham Biosciences) in $0.15 \mathrm{M}$ sodium chloride containing $1 \mathrm{mM}$ EDTA and $0.02 \%$ sodium azide, $\mathrm{pH} 7.4$, and $0.25-\mathrm{ml}$ fractions were collected $(0.1 \mathrm{ml} / \mathrm{min})$. Equal volumes of the $\delta<1.006 \mathrm{~g} / \mathrm{ml}$ float fraction were concentrated on the Microcon-30s (Millipore), and proteins were resolved by SDS-PAGE on 4\%-15\% Ready Gels (Bio-Rad). Proteins were visualized by Coomassie blue and silver staining.

VLDL plasma clearance. Human VLDL $(\delta<1.006 \mathrm{~g} / \mathrm{ml})$ was isolated by ultracentrifugation from healthy, fasting volunteers. All volunteers gave informed consent, as required by the UCSD IACUC. Mice were fasted for 6 hours and injected with $10 \mu \mathrm{g}$ human VLDL protein via the tail vein. Serial samples were taken by retroorbital bleeds at the indicated times. The amount of human VLDL remaining in the plasma was determined by sandwich ELISA, utilizing mAb MB47 specific for human apoB-100 (75). MB47 does not bind to murine apoB-100, and therefore it can be used to trace the clearance of injected human VLDL. U-bottom 96-well plates were coated overnight with MB47 at $5 \mu \mathrm{g} / \mathrm{ml}$ in Tris-buffered saline, followed by addition of nonsaturating amounts of plasma (typically, 1:100 dilution of mouse plasma) to capture human VLDL. Bound VLDL was detected using biotinylated goat anti-human apoB-100 (BIODESIGN International), followed by alkaline phosphatase-labeled neutrAvidin (Pierce Biotechnology). Plates were developed with Lumi-Phos 530 (Lumigen) and read in a DYNEX Technologies MLX Microtiter Plate Luminometer.

Vitamin A excursion studies. Clearance of chylomicrons derived from dietary triglyceride was measured by Vitamin A excursion essentially as described (24). Briefly, $27 \mu \mathrm{Ci}$ of $\left[11,12-{ }^{3} \mathrm{H}\right]$-retinol (PerkinElmer; $44.4 \mathrm{Ci} / \mathrm{mmol}$ ) in ethanol was mixed with $1 \mathrm{ml}$ of corn oil (Sigma-Aldrich) and administered by oral gavage ( $200 \mu \mathrm{l} /$ mouse). Retroorbital sinus blood was sampled at the times indicated, and radioactivity was measured in triplicate $(10 \mu \mathrm{l}$ of serum) by scintillation counting. Triglycerides were measured enzymatically using a plate reader and kits.

Immunofluorescence microscopy. Livers were perfused at $7 \mathrm{ml} / \mathrm{min}$ with $30 \mathrm{ml}$ of PBS/EDTA followed by $30 \mathrm{ml}$ of $4 \%$ paraformaldehyde. Livers were snap-frozen, and $20-\mu \mathrm{m}$ sections were cut on a cryostat. Sections were plated on glass coverslips precoated with laminin $\left(2 \mu \mathrm{g} / \mathrm{cm}^{2}\right)$. They were then fixed with $2 \%$ paraformaldehyde in PBS for 10 minutes at room temperature, incubated for 10 minutes with $100 \mathrm{mM}$ glycine, $\mathrm{pH}$ 7.4, to quench aldehyde groups, permeabilized in $0.1 \%$ Triton X-100 for 10 minutes, blocked for 20 minutes with a solution of $1 \%$ BSA and $0.05 \%$ Tween in PBS, and then incubated for 2 hours at room temperature with primary antibodies (syndecan-1, 1:250; syndecan-2, 1:250; syndecan-4, 1:100) in blocking solution. Rabbit polyclonal antibodies raised against the various syndecans were a gift of A. Rapraeger (University of Wisconsin, Madison, Wisconsin, USA). Excess antibody was removed by incubation for 15 minutes with $0.1 \%$ Tween in PBS. Samples were then incubated for 1 hour with Alexa Fluor 594-conjugated goat anti-rabbit secondary antibody (1:250; Invitrogen) and then washed 6 times at 5 -minute intervals with $0.1 \%$ Tween in PBS and incubated for 20 minutes with the nuclear stain DAPI $(1: 5,000)$ diluted in PBS. Images were captured with a DeltaVision Restoration microscope system (AppliedPrecision) using a Photometrics Sony CoolSAP HQ charge-coupled device camera system attached to an inverted, wide-field fluorescence microscope (Nikon TE200). Optical sections were acquired using a $\times 63$ Nikon (NA 1.3) oil-immersion objective in $0.2-\mu \mathrm{m}$ steps on the $z$ axis. Fluorescence was detected using a standard DAPI and Texas Red filter set. Images were saved, processed, and analyzed on SGI workstations (O2; Octane) using the DeltaVision software package softWoRx (version 2.50). Quantification of fluorescence was accomplished using only the linear range of the digital camera.

Immunogold electron microscopy. Samples were fixed in $4 \%$ paraformaldehyde in $10 \mathrm{mM}$ phosphate buffer, $\mathrm{pH} 7.4$, cryoprotected, and frozen in liquid nitrogen. Ultrathin cryosections were cut at $4^{\circ} \mathrm{C}$ using a Leica Ultracut UCT Microtome with an EMFCS cryoattachment (Leica) and placed on glow-discharged nickel grids. Samples were stored on $2 \%$ gelatin in PBS at $4{ }^{\circ} \mathrm{C}$ and incubated with rabbit anti-mouse syndecan- 1 polyclonal antibody followed by goat anti-rabbit IgG conjugated to 5- or 
10-nm gold particles (Amersham Biosciences) in PBS supplemented with $10 \%$ FBS. Grids were absorption-stained with $0.2 \%$ neutral uranyl acetate, $0.2 \%$ methylcellulose, and $3.2 \%$ polyvinyl alcohol. Images were obtained using a JEOL 1200EX II transmission electron microscope and photographed using a Gatan digital camera.

Lipoprotein binding and uptake by hepatocytes. Human VLDL $(\delta<1.006 \mathrm{~g} / \mathrm{ml}$, $\sim 1.1 \mathrm{mg}$ protein) was iodinated using $3 \mathrm{mCi}$ of $\mathrm{Na}^{125} \mathrm{I}$ (NEN, PerkinElmer) using Iodogen (76). Under these conditions, the final radiospecific activity was $1.4 \times 10^{2} \mathrm{cpm} / \mathrm{ng}$ and $13 \%$ of the label was lipid soluble. Isolated hepatocytes were treated with the indicated concentration of ${ }^{125} \mathrm{I}-\mathrm{VLDL}$ in DMEM media with $2.5 \mathrm{mg} / \mathrm{ml}$ lipoprotein-free serum (Biomedical Technologies Inc.). Cells were incubated at $4^{\circ} \mathrm{C}$ or $37^{\circ} \mathrm{C}$ for 1 hour, rinsed 3 times with PBS, and then solubilized with $0.1 \mathrm{M}$ sodium hydroxide. Protein concentration was determined by Bradford assay (BioRad), and radioactivity was measured by $\gamma$ counting. Degradation of ${ }^{125}$ I-VLDL was measured by precipitation of $0.25 \mathrm{ml}$ of conditioned media with an equal volume of $50 \%$ trichloroacetic acid (16). After 30 minutes at $4{ }^{\circ} \mathrm{C}$, the samples were centrifuged for 30 minutes. The supernatant was placed in a fresh glass tube, and $5 \mu$ l of $40 \%$ potassium iodide was added as a carrier. Hydrogen peroxide (30\%) was added, and lipid-soluble material was extracted by the addition of $2 \mathrm{ml}$ of chloroform. An aliquot of the upper aqueous phase containing iodotyrosine was counted as measure of degradation.

Porcine intestinal heparin $\left(\mathrm{M}_{r}=12,000-15,000,180 \mathrm{U} / \mathrm{mg}\right)$ was a gift from P. Shaklee (Scientific Protein Laboratories Inc., Waunakee, Wisconsin, USA). In competition experiments, wild-type hepatocytes were treated simultane- ously with varying concentrations of heparin and ${ }^{125} \mathrm{I}-\mathrm{VLDL}$ and incubated at $4^{\circ} \mathrm{C}$ for 1 hour. The signal obtained in the presence of heparin was subtracted from the total binding in order to calculate specific binding.

Statistics. Statistical analyses were performed using PRISM (GraphPad Software). All data are expressed as mean values \pm SD unless otherwise indicated. Significance was determined using an unpaired Student's (2-tailed) $t$ test or ANOVA with Bonferroni post-hoc analysis. Significance was taken as $P<0.05$.

\section{Acknowledgments}

We would like to thank Joseph Juliano, Fely Alamazen, and Jennifer Pattison at UCSD and David Ditto of the Hematology/Coagulation/Chemistry Core, UCSD, for excellent technical assistance. This work was supported by NIH grants GM33063 and HL57345 (to J.D. Esko) and HL088093 (to J.L. Witztum) and by the Leducq Foundation (to J.L. Witztum) and a Scientist Development Grant from the American Heart Association (to J.R. Bishop).

Received for publication December 5, 2008, and accepted in revised form July 29, 2009.

Address correspondence to: Jeffrey D. Esko, Department of Cellular and Molecular Medicine, University of California, San Diego, La Jolla, California 92093-0687, USA. Phone: (858) 822-1100; Fax: (858) 534-5611; E-mail: jesko@ucsd.edu.
1. Nordestgaard, B.G., Benn, M., Schnohr, P., and Tybjaerg-Hansen, A. 2007. Nonfasting triglycerides and risk of myocardial infarction, ischemic heart disease, and death in men and women. JAMA 298:299-308.

2. Bansal, S., et al. 2007. Fasting compared with nonfasting triglycerides and risk of cardiovascular events in women. JAMA. 298:309-316.

3. Beigneux, A.P., et al. 2007. Glycosylphosphatidylinositol-anchored high-density lipoprotein-binding protein 1 plays a critical role in the lipolytic processing of chylomicrons. Cell Metab. 5:279-291.

4. Young, S.G., et al. 2007. GPIHBP1: an endothelial cell molecule important for the lipolytic processing of chylomicrons. Curr. Opin. Lipidol. 18:389-396.

5. Williams, K.J., and Fuki, I.V. 1997. Cell-surface heparan sulfate proteoglycans: dynamic molecules mediating ligand catabolism. Curr. Opin. Lipidol. 8:253-262.

6. Mahley, R.W., and Ji, Z.S. 1999. Remnant lipoprotein metabolism: key pathways involving cell-surface heparan sulfate proteoglycans and apolipoprotein E. J. Lipid Res. 40:1-16.

7. Mahley, R.W., and Huang, Y. 2007. Atherogenic remnant lipoproteins: role for proteoglycans in trapping, transferring, and internalizing. J. Clin. Invest. 117:94-98.

8. Williams, K.J. 2008. Molecular processes that handle - and mishandle - dietary lipids. J. Clin. Invest. 118:3247-3259.

9. MacArthur, J.M., et al. 2007. Liver heparan sulfate proteoglycans mediate clearance of triglyceriderich lipoproteins independently of LDL receptor family members. J. Clin. Invest. 117:153-164.

10. Bishop, J.R., Stanford, K.I., and Esko, J.D. 2008. Heparan sulfate proteoglycans and triglyceriderich lipoprotein metabolism. Curr. Opin. Lipidol. 19:307-313.

11. Shintani, Y., et al. 2006. Glycosaminoglycan modification of neuropilin-1 modulates VEGFR2 signaling. EMBO J. 25:3045-3055.

12. Bishop, J.R., Schuksz, M., and Esko, J.D. 2007. Heparan sulphate proteoglycans fine-tune mammalian physiology. Nature. 446:1030-1037.
13. Fuki, I.V., et al. 1997. The syndecan family of proteoglycans. Novel receptors mediating internalization of atherogenic lipoproteins in vitro. J. Clin. Invest. 100:1611-1622.

14. Fuki, I.V., Iozzo, R.V., and Williams, K.J. 2000. Perlecan heparan sulfate proteoglycan - A novel receptor that mediates a distinct pathway for ligand catabolism. J. Biol. Chem. 275:25742-25750.

15. Wilsie, L.C., Gonzales, A.M., and Orlando, R.A. 2006. Syndecan-1 mediates internalization of apoE-VLDL through a low density lipoprotein receptor-related protein (LRP)-independent, nonclathrin-mediated pathway. Lipids Health Dis. 5:23.

16. Williams, K.J. 2001. Interactions of lipoproteins with proteoglycans. Methods Mol. Biol. 171:457-477.

17. Ebara, T., et al. 2000. Delayed catabolism of apoB48 lipoproteins due to decreased heparan sulfate proteoglycan production in diabetic mice. J. Clin. Invest. 105:1807-1818.

18. Tran-Lundmark, K., et al. 2008. Heparan sulfate in perlecan promotes mouse atherosclerosis: roles in lipid permeability, lipid retention, and smooth muscle cell proliferation. Circ. Res. 103:43-52.

19. Zeng, B.J., Mortimer, B.C., Martins, I.J., Seydel, U., and Redgrave, T.G. 1998. Chylomicron remnant uptake is regulated by the expression and function of heparan sulfate proteoglycan in hepatocytes. J. Lipid Res. 39:845-860.

20. Yu, K.C., Chen, W., and Cooper, A.D. 2001. LDL receptor-related protein mediates cell-surface clustering and hepatic sequestration of chylomicron remnants in LDLR-deficient mice. J. Clin. Invest. 107:1387-1394.

21. Fuki, I.V., Meyer, M.E., and Williams, K.J. 2000. Transmembrane and cytoplasmic domains of syndecan mediate a multi-step endocytic pathway involving detergent-insoluble membrane rafts. Biochem. J. 351:607-612.

22. Cortes, V., et al. 2007. Adenovirus-mediated hepatic syndecan-1 overexpression induces hepatocyte proliferation and hyperlipidaemia in mice. Liver Int. 27:569-581.

23. Weiner, O.H., Zoremba, M., and Gressner, A.M. 1996. Gene expression of syndecans and betaglycan in isolated rat liver cells. Cell Tissue Res. 285:11-16.

24. Ishibashi, S., et al. 1996. Role of the low density lipoprotein (LDL) receptor pathway in the metabolism of chylomicron remnants. A quantitative study in knockout mice lacking the LDL receptor, apolipoprotein E, or both. J. Biol. Chem. 271:22422-22427.

25. Horton, J.D., et al. 1999. Disruption of LDL receptor gene in transgenic SREBP-1a mice unmasks hyperlipidemia resulting from production of lipidrich VLDL. J. Clin. Invest. 103:1067-1076.

26. Alexander, C.M., et al. 2000. Syndecan-1 is required for Wnt-1-induced mammary tumorigenesis in mice. Nat. Genet. 25:329-332.

27. Hirano, T., et al. 2001. Apoprotein C-III deficiency markedly stimulates triglyceride secretion in vivo: comparison with apoprotein E. Am. J. Physiol. Endocrinol. Metab. 281:E665-E669.

28. Weinstein, M.M., et al. 2008. Abnormal patterns of lipoprotein lipase release into the plasma in GPIHBP1-deficient mice. J. Biol. Chem. 283:34511-34518.

29. Ishibashi, S., et al. 1993. Hypercholesterolemia in low density lipoprotein receptor knockout mice and its reversal by adenovirus-mediated gene delivery. J. Clin. Invest. 92:883-893.

30. Hayashi, K., et al. 1987. Immunocytochemistry of cell surface heparan sulfate proteoglycan in mouse tissues. A light and electron microscopic study. J. Histochem. Cytochem. 35:1079-1088.

31. Roskams, T., et al. 1995. Heparan sulfate proteoglycan expression in normal human liver. Hepatology. 21:950-958.

32. Higazi, A.A., et al. 2000. The alpha-defensins stimulate proteoglycan-dependent catabolism of lowdensity lipoprotein by vascular cells: a new class of inflammatory apolipoprotein and a possible contributor to atherogenesis. Blood. 96:1393-1398.

33. Anisfeld, A.M., et al. 2003. Syndecan-1 expression is regulated in an isoform-specific manner by the farnesoid-X receptor. J. Biol. Chem. 278:20420-20428.

34. Williams, K.J., et al. 1992. Mechanisms by which lipoprotein lipase alters cellular metabolism of lipoprotein(a), low density lipoprotein, and nascent lipoproteins. Roles for low density lipoprotein 
receptors and heparan sulfate proteoglycans. J. Biol. Chem. 267:13284-13292.

35. Ji, Z.S., et al. 1993. Role of heparan sulfate proteoglycans in the binding and uptake of apolipoprotein E-enriched remnant lipoproteins by cultured cells. J. Biol. Chem. 268:10160-10167.

36. Feussner, G., et al. 1996. Apolipoprotein E5

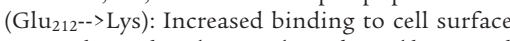
proteoglycans but decreased uptake and lysosomal degradation in cultured fibroblasts. J. Lipid Res. 37:1632-1645

37. Krapp, A., et al. 1996. Hepatic lipase mediates the uptake of chylomicrons and $\beta$-VLDL into cells via the LDL receptor-related protein (LRP). J. Lipid Res. 37:926-936.

38. Al-Haideri, M., et al. 1997. Heparan sulfate proteoglycan-mediated uptake of apolipoprotein E-triglyceride-rich lipoprotein particles: a major pathway at physiological particle concentrations. Biochemistry. 36:12766-12772.

39. Huff, M.W., et al. 1997. Uptake of hypertriglyceridemic very low density lipoproteins and their remnants by HepG2 cells: the role of lipoprotein lipase, hepatic triglyceride lipase, and cell surface proteoglycans. J. Lipid Res. 38:1318-1333.

40. Ji, Z.S., Pitas, R.E., and Mahley, R.W. 1998. Differential cellular accumulation/retention of apolipoprotein $\mathrm{E}$ mediated by cell surface heparan sulfate proteoglycans. Apolipoproteins E3 and E2 greater than e4. J. Biol. Chem. 273:13452-13460.

41. Seo, T., et al. 2000. Lipoprotein lipase-mediated selective uptake from low density lipoprotein requires cell surface proteoglycans and is independent of scavenger receptor class B type 1. J. Biol. Chem. 275:30355-30362.

42. Medh, J.D., et al. 2000. Lipoprotein lipase- and hepatic triglyceride lipase- promoted very low density lipoprotein degradation proceeds via an apolipoprotein E-dependent mechanism. J. Lipid Res. 41:1858-1871.

43. Bernfield, M., et al. 1992. Biology of the syndecans: a family of transmembrane heparan sulfate proteoglycans. Annu. Rev. Cell Biol. 8:365-393.

44. Bernfield, M., et al. 1999. Functions of cell surface heparan sulfate proteoglycans. Annu. Rev. Biochem. 68:729-777.

45. Park, P.W., Reizes, O., and Bernfield, M. 2000. Cell surface heparan sulfate proteoglycans: Selective regulators of ligand-receptor encounters. J. Biol. Chem. 275:29923-29926.

46. Bellin, R., et al. 2002. Unlocking the secrets of syndecans: Transgenic organisms as a potential key. Glycoconj. J. 19:295-304.

47. Sanderson, R.D., and Yang, Y. 2008. Syndecan-1: a dynamic regulator of the myeloma microenvironment. Clin. Exp. Metastasis. 25:149-159.
48. Bartlett, A.H., Hayashida, K., and Park, P.W. 2007. Molecular and cellular mechanisms of syndecans in tissue injury and inflammation. Mol. Cells. 24:153-166.

49. Tumova, S., Woods, A., and Couchman, J.R. 2000. Heparan sulfate proteoglycans on the cell surface: versatile coordinators of cellular functions. Int. J. Biochem. Cell Biol. 32:269-288.

50. Burbach, B.J., Friedl, A., Mundhenke, C., and Rapraeger, A.C. 2003. Syndecan-1 accumulates in lysosomes of poorly differentiated breast carcinoma cells. Matrix Biol. 22:163-177.

51. Fitzgerald, M.L., Wang, Z.H., Park, P.W., Murphy, G., and Bernfield, M. 2000. Shedding of syndecan-1 and -4 ectodomains is regulated by multiple signaling pathways and mediated by a TIMP-3-sensitive metalloproteinase. J. Cell Biol. 148:811-824.

52. Parthasarathy, N., et al. 1994. Oligosaccharide sequences of endothelial cell surface heparan sulfate proteoglycan with affinity for lipoprotein lipase. J. Biol. Chem. 269:22391-22396.

53. Spillmann, D., Lookene, A., and Olivecrona, G. 2006. Isolation and characterization of low sulfated heparan sulfate sequences with affinity for lipoprotein lipase. J. Biol. Chem. 281:23405-23413.

54. Libeu, C.P., et al. 2001. New insights into the heparan sulfate proteoglycan-binding activity of apolipoprotein E. J. Biol. Chem. 276:39138-39144.

55. Dong, J., et al. 2001. Interaction of the N-terminal domain of apolipoprotein E4 with heparin. Biochemistry. 40:2826-2834.

56. Lyon, M., Deakin, J.A., and Gallagher, J.T. 1994. Liver heparan sulfate structure. A novel molecular design. J. Biol. Chem. 269:11208-11215.

57. Vongchan, P., et al. 2005. Structural characterization of human liver heparan sulfate. Biochim. Biophys. Acta. 1721:1-8.

58. Thankamony, S.P., and Knudson, W. 2006. Acylation of CD44 and its association with lipid rafts are required for receptor and hyaluronan endocytosis. J. Biol. Chem. 281:34601-34609.

59. Tkachenko, E., Lutgens, E., Stan, R.V., and Simons, M. 2004. Fibroblast growth factor 2 endocytosis in endothelial cells proceed via syndecan-4-dependent activation of Rac1 and a Cdc42-dependent macropinocytic pathway. J. Cell Sci. 117:3189-3199.

60. Brown, M.S., Anderson, R.G., and Goldstein, J.L. 1983. Recycling receptors: the round-trip itinerary of migrant membrane proteins. Cell. 32:663-667.

61. Rohlmann, A., Gotthardt, M., Hammer, R.E., and Herz, J. 1998. Inducible inactivation of hepatic LRP gene by cre-mediated recombination confirms role of LRP in clearance of chylomicron remnants. J. Clin. Invest. 101:689-695.

62. Wilsie, L.C., and Orlando, R.A. 2003. The low density lipoprotein receptor-related protein complexes with cell surface heparan sulfate proteoglycans to regulate proteoglycan-mediated lipoprotein catabolism. J. Biol. Chem. 278:15758-15764.

63. Magoori, K., et al. 2003. Severe hypercholesterolemia, impaired fat tolerance, and advanced atherosclerosis in mice lacking both low density lipoprotein receptor-related protein 5 and apolipoprotein $\mathrm{E}$. J. Biol. Chem. 278:11331-11336.

64. Belting, M. 2003. Heparan sulfate proteoglycan as a plasma membrane carrier. Trends Biochem. Sci. 28:145-151.

65. Elson-Schwab, L., et al. 2007. Guanidinylated neomycin delivers large, bioactive cargo into cells through a heparan sulfate-dependent pathway. J. Biol. Chem. 282:13585-13591.

66. Park, P.W., Pier, G.B., Hinkes, M.T., and Bernfield, M. 2001. Exploitation of syndecan-1 shedding by Pseudomonas aeruginosa enhances virulence. Nature. 411:98-102.

67. Reizes, O., et al. 2001. Transgenic expression of syndecan-1 uncovers a physiological control of feeding behavior by syndecan-3. Cell. 106:105-116.

68. Echtermeyer, F., et al. 2001. Delayed wound repair and impaired angiogenesis in mice lacking syndecan-4. J. Clin. Invest. 107:R9-R14.

69. Seglen, P.O. 1976. Preparation of isolated rat liver cells. Methods Cell Biol. 13:29-83.

70. Hayashida, K., Johnston, D.R., Goldberger, O., and Park, P.W. 2006. Syndecan-1 expression in epithelial cells is induced by transforming growth factor beta through a PKA-dependent pathway. J. Biol. Chem. 281:24365-24374.

71. Dulbecco, R., and Vogt, M. 1954. Plaque formation and isolation of pure cell lines with poliomyelitis viruses. J. Exp. Med. 99:167-182.

72. Rohlmann, A., Gotthardt, M., Willnow, T.E., Hammer, R.E., and Herz, J. 1996. Sustained somatic gene inactivation by viral transfer of Cre recombinase. Nat. Biotechnol. 14:1562-1565.

73. Bishop, J.R., and Esko, J.D. 2005. The elusive role of heparan sulfate in Toxoplasma gondii infection. Mol. Biochem. Parasitol. 139:267-269.

74. Livak, K.J., and Schmittgen, T.D. 2001. Analysis of relative gene expression data using real-time quantitative PCR and the 2(-Delta Delta C(T)) Method. Methods. 25:402-408.

75. Young, S.G., Smith, R.S., Hogle, D.M., Curtiss, L.K. and Witztum, J.L. 1986. Two new monoclonal antibody-based enzyme-linked assays of apolipoprotein B. Clin. Chem. 32:1484-1490.

76. Salacinski, P.R., McLean, C., Sykes, J.E., ClementJones, V.V., and Lowry, P.J. 1981. Iodination of proteins, glycoproteins, and peptides using a solidphase oxidizing agent, 1,3,4,6-tetrachloro-3 alpha, 6 alpha-diphenyl glycoluril (Iodogen). Anal. Biochem. 117:136-146 